to that obtained under the same experimental conditions with human menopausal gonadotrophin and human chorionic gnnadotrophin.

We thank Miss Elena Altieri for urinary pregnanediol determinations, Mrs. Elizabeth Grassau for help with the manuscript, and Mr. Rene Roy for photography and illustrations.

The compounds used in this study were generously supplied as follows: Synthetic FSH/LH-RH (AY-24031) from Dr. M. Gahwyler, Ayerst International, New York, N.Y., U.S.A., Medroxyprogesterone Acetate (Depo-Provera) The Upjohn Company, Kalamazoo, Michigan, U.S.A., Chlormadinone Acetate (Gestafortin) Merck, Darmstadt, West Germany.

\section{References}

Akande, E. O., et al. (1972). Lancet, 2, 112.

Kastin, A. J., Schally, A. V., Gual, C., and Arimura, A. (1972 a). Fournal of Clinical Endocrinology and Metabolism, 34, 753.

Kastin, A. J., Gual, C., and Schally, A. V.'(1972 b). Recent Progress in Hormone Research, 28, 201.

Schally, A. V., et al. (1971 a). Science, 173, 1036.

Schally, A. V.., Kastin, A. J., and Arimura, A. (1971 b). Fertility and Sterility, 22, 703 .

Schally, A. V., Kastin, A. J., and Arimura, A. (1972). American fournal of Obstetrics and Gynecology, 114, 423.

Sulimovici, S., Lunenfeld, S., and Shelesnyak, M. C. (1965). Acta Endocrinologica Kpbenhavn, 49, 97.

Yen, S. S. C., et al. (1972). Fournal of Clinical Endocrinology and Metabolism, 34, 1108 .

Zanartu, J., Dabancens, A., Kastin, A. J., and Schally, A. V. (1974). In press.

Zanartu, J., et al. (1970). Fertility and Sterility, 21, 525.

Zanartu, J., and Onetto, E. (1974). Australian and New Zealand fournal of Obstetrics and Gynaecology. In press.

Zarate, A., Canales, E. S., Schally, A. V., Ayala-Valdez, L., and Kastin, A (1972). Fournal of Fertility and Sterility, 23, 672.

\title{
Endoscopic Pancreatography in Management of Relapsing Acute Pancreatitis
}

\author{
P. B. COTTON, J. S. M. BEALES
}

British Medical fournal, 1974, 1, 608-611

\begin{abstract}
Summary
Endoscopic retrograde cholangiopancreatography (E.R.C.P.) was attempted in 31 patients suffering from repeated attacks of acute pancreatitis. Pancreatograms were obtained in 25 patients. Twelve showed definite "surgical lesions" (obstructions, strictures, or pseudocysts). In at least three patients failure to obtain a pancreatogram was due to obstruction of pancreatic duct close to the papilla. Two patients, both with pseudocysts, developed a mild relapse of pancreatitis after the procedure. Surgical intervention based on the x-ray findings seemed beneficial in the short follow-up period.

Endoscopic pancreatography can be of value in deciding when surgery is advisable for patients with relapsing acute pancreatitis and in determining the operative appreach. It is an advance in the management of a difficult clinical condition.
\end{abstract}

\section{Introduction}

In Britain about one-third of patients who survive an attack of acute pancreatitis have at least one recurrence (Trapnell, 1966). In some of them a previously overlooked contributory factor (such as gall stones or alcoholism) is found which may be remediable. In others, however, there is no apparent explanation for their recurrent acute relapses. These cases pose problems in management-in panticular, whether to recommend surgery and what operation. Information about the state of the pancreatic duot and its drainage should be of help. Until recently pancreatography was possible only at laparotomy (Doubilet et al., 1959) after a duodenotomy, which

St. Thomas's Hospital, London SE1 7EH

P. B. COTTON, M.D., M.R.C.P., Senior Medical Registrar (Present appointment: Consultant Physician, Middlesex Hospital, London W.1)

J. S. M. BEALES, M.R.C.P., F.F.R., Consultant Radiologist (Present appointment: Consultant Radiologist, Royal United Hospital, Bath) increased the risk of explanatory surgery. Owing to the recent development of fibreoptic duodenoscopes the papilla of Vater can now be cannulated by endoscopy in conscious, sedated patients and contrast medium for radiography injected into the pancreatic ducts and biliary system. After the original Japanese studies (Ogoshi et al., 1970; Oi et al., 1970; Takagi et al., 1970; Kasugai et al., 1972) many encouraging reports of the technique came from Western Europe and Nonth America (Jean-pierre et al., 1971; Blumgart et al., 1972; Classen et al., 1972; Cotton et al., 1972; Cotton, 1972; Vennes and Silvis, 1972). In experienced hands the success rate is about $90 \%$.

Endoscopic retrograde cholangiography has obvious potential in the diagnosis of patients with difficult jaundice (Blumgant et al., 1972) but the clinical role of endoscopic retrograde pancreatography has yet to be defined. This paper reponts our use of it in cases of relapsing acute pancreatitis and our experience of its value as a guide to their management.

\section{Patients and Methods}

A total of 31 patients were investigated. Five were women (aged 63, 58, 62, 23, and 79 years respectively) and 26 were men (mean age 43 years, range 21-72 years). Two patients came from India, one from Iceland, and the remainder from the United Kingdom and Ireland. Five had had only one major attack of acute pancreatitis but had continued to have recurrent episodes of pain needing funther hospital investigation. The remaining patients had had from two to 20 attacks of acute pancreatitis over a period of up to 15 years. Four patients had undergone cholecysteotomy for stones and another patient had been suspected of having a gall bladder stone on cholecystography. Fifteen of the patients drank alcohol rarely, if at all, nine drank alcohol every day but not excessively, and seven patients regularly drank more than one litre of beer or three (English) measures of spirits daily. None of the patients had hypercalcaemia and none out of 21 patients tested had any striking abnormality of serum cholesterol or triglycerides. Two patients were being treated with thiazide diuretics. Two patients had had surgery for peptic ulcera- 
tion (Billroth I gastrectomy and vagotomy and pyloroplasty); nine had undergone diagnostic laparotomy during an attack of pancreatitis; three had had an eleotive sphinoteroplasty; and one had had a repair of a peripapillary diventiculum. Oral cholecystography or intravenous cholangiography had been carried out in all patients with negative results, except in the case mentioned above. In none of the patients did barium meal radiography suggest the presence of a pseudocyst.

All the patients were admitted to hospital and were examined in the standand manner in the $x$-ray department under diazepam sedation (Cotton, 1972). An Olympus JFB duodenoscope was passed through the stomach and duodenal bulb into the descending duodenum. After careful examination of these organs and taking specimens for biopsy when indicated the instrument was adjusted to provide a face-on view of the papilla of Vater. A Teflon catheter $(1.7 \mathrm{~mm}$ diameter) was passed through the instrument and guided into the papilla. Urografin (sodium and meglumine diatrizoates) $60 \%$ was then injected slowly under fluoroscopic control to opacify the panoreatic duot and its major branches. Radiographs were taken in appropriate positions. The time for the whole procedure was usually between 30 and 45 minutes.

\section{Results}

The endoscopic appearance of the duodenal loop was abnormal in only 11 patients. In seven the mucosa of the floor of the bulb and the medial wall of the descending duodenum showed abnormally large or congested folds but in only one of these cases was the biopsy specimen definitely abnormal. In three patients the papilla of Vater was abnormal because of previous sphinoteroplasty and in another there was scarring from repair of a diventiculum. In one patient a previously unsuspected diventiculum obscured the papilla and prevented cannulation. Apant from this case the papilla was seen and cannulated in all the patients. Subsequent injection of contrast medium resulted in a pancreatogram in 25 patients, but in the remaining five no medium passed up the pancreatic duot despite repeated attempts.

Thirteen of the 25 pancreatograms showed no "surgical lesion" (table). The appearances were nommal in four (see fig. 1) and the other nine showed minor variations in duot calibre (figs. 2 and 3). In two of these only the branch ducts were abnormal. The remaining 12 pancreatograms showed a "surgical lesion." In four cases there was complete obstruction of the main pancreatic duot (fig. 4). In five there were localized striotures (four juxtapapillary and one in the body; fig. 5) and in the remaining three strictures were associated with pseudocysts (two in the body and one in the tail; fig. 6). There were no striking differences between the radiological appearances of patients who abused alcohol and those who did not.

Results of Pancreatography in patients with Relapsing Acute Pancreatitis

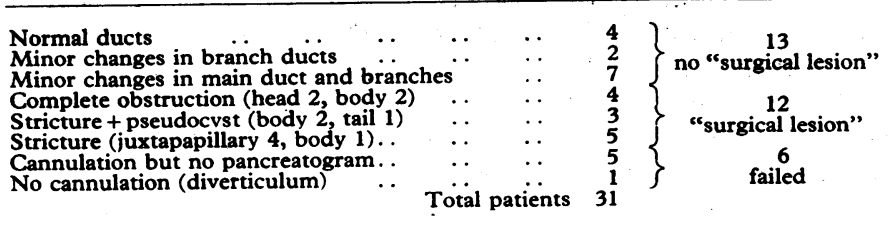

Retrograde Cholangiography.-Injection of contrast medium into the papilla resulted in cholangiograms as well as pancreatograms in 13 of the 31 patients. In one case the cholangiogram confirmed the suspicion of a gall bladder stone reported at previous cholangiography. The remaining examinations showed no sigmificant abnormality. Retrograde

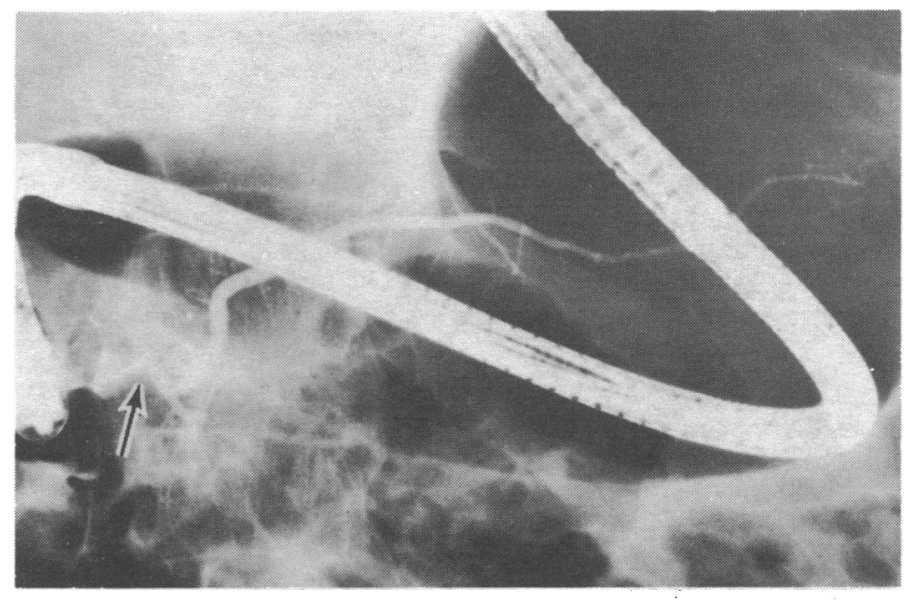

FIG. 1-Normal pancreatogram in man aged 39 with history of five attacks of acute pancreatitis. Tip of cannula is at papilla of Vater (arrowed).

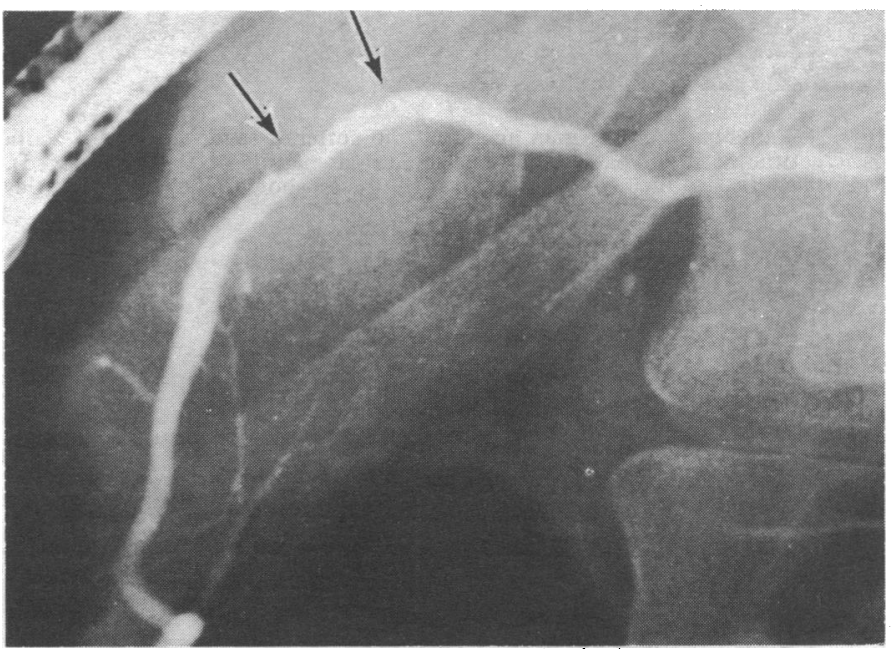

FIG. 2-Pancreatogram in man aged 31 with persistent pain after attack of acute pancreatitis. Slight irregularity of main pancreatic duct in head of pancreas (arrowed) with no filling of the branches from the abnormal segment. No surgical lesion.

cholangiography was not attempted as a routine in every patient, since the results of previous cholecystograms or infusion cholangiograms had been normal in all of them (apart from the one already mentioned).

Complications.-Two patients had mild relapses of pancreatitis after the examination; both had previously been having frequent attacks of pain and both were shown to have pseudocysts. Treatment with antibiotios was followed by elective sungery within a week.

Pancreatic Function Studies.-A secretin/pancreozymin test was performed in 16 patients and 10 of them were subsequently shown to have "surgical lesions" of the pancreas. Bicarbonate and enzyme secretion was normal in four of these 10 patients, equivocal in one, and grossly abnormal in five.

\section{SUBSEQUENT PROGRESS}

The clinical progress of the patients was followed over periods of from three months to two years. Many of them were from other hospitals and they were subsequently treated by the clinicians who had referred them. Their decisions were 


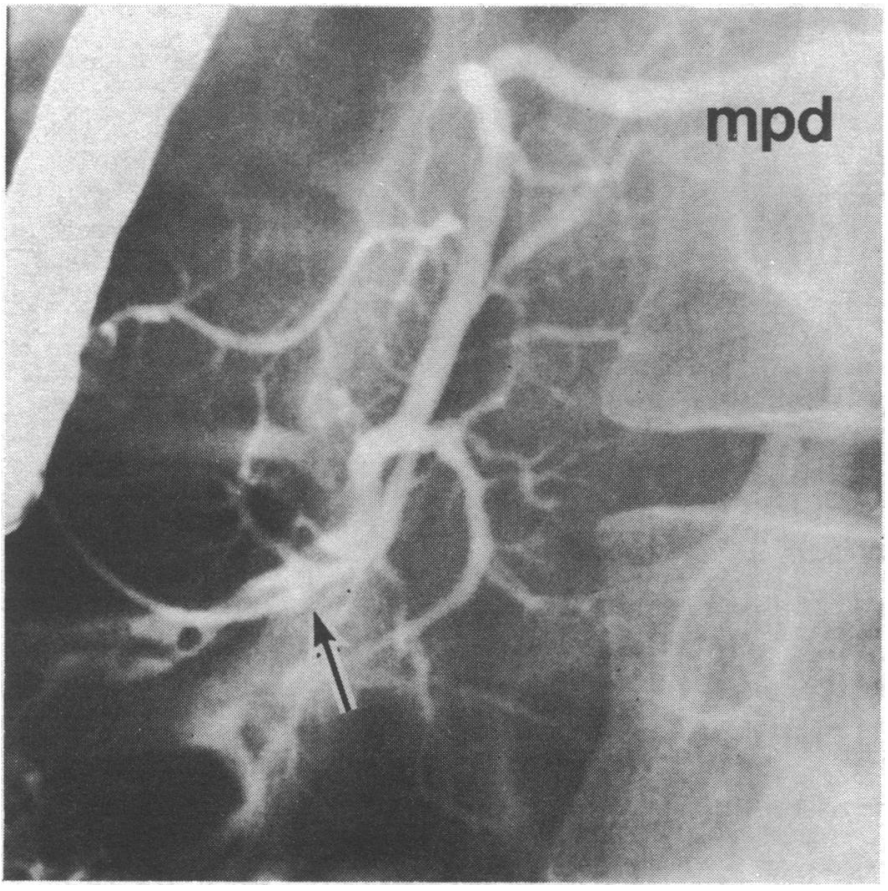

FIG. 3-Pancreatogram in man aged 34 who suffered seven attacks of acute pancreatitis in three years. Tip of cannula is at papilla of Vater (arrowed). Main pancreatic duct (mpd) and branch ducts show minor irregularities and calibre variations. No surgical lesion.

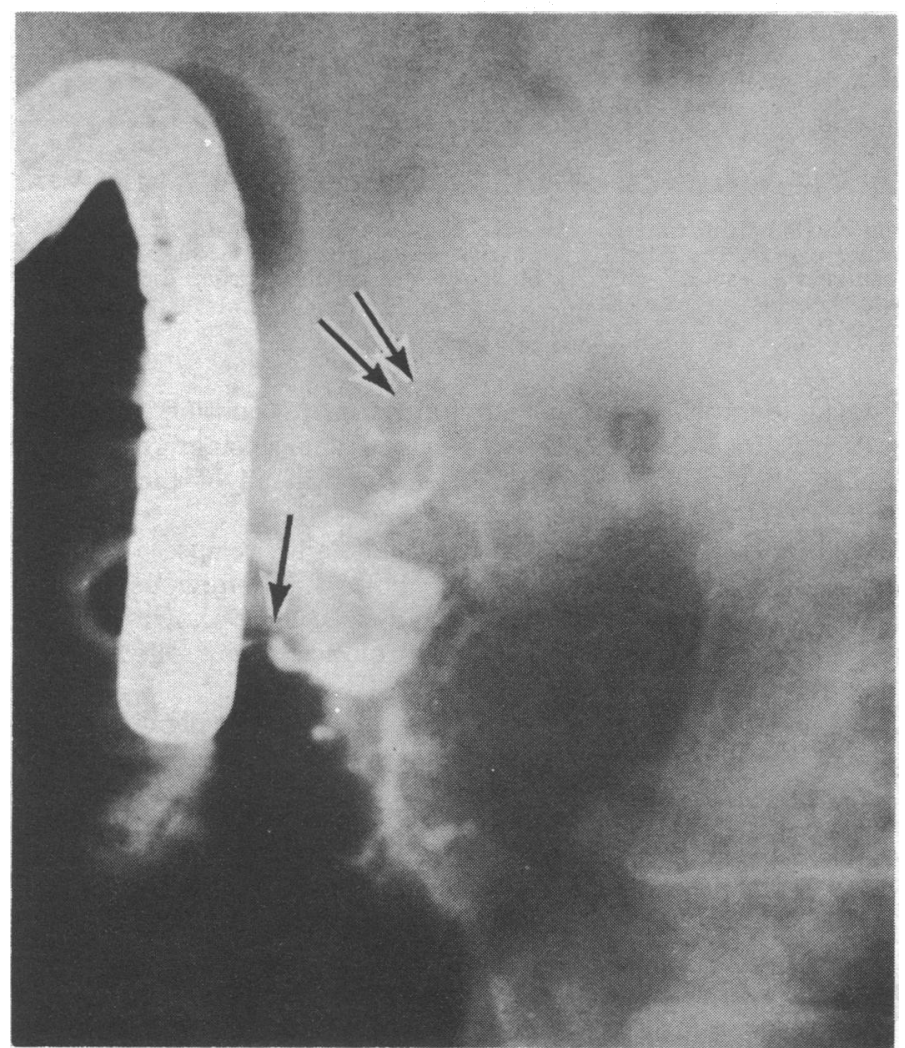

FIG. 4-Pancreatogram in man aged 44 who suffered three episodes of pancreatitis. Complete obstruction of main pancreatic duct (double arrows) about $3 \mathrm{~cm}$ from papilla (single arrow). Branch ducts in head of pancreas irregular. At laparotomy distal part of pancreatic duct was found to be dilated and was anastomosed to stomach.

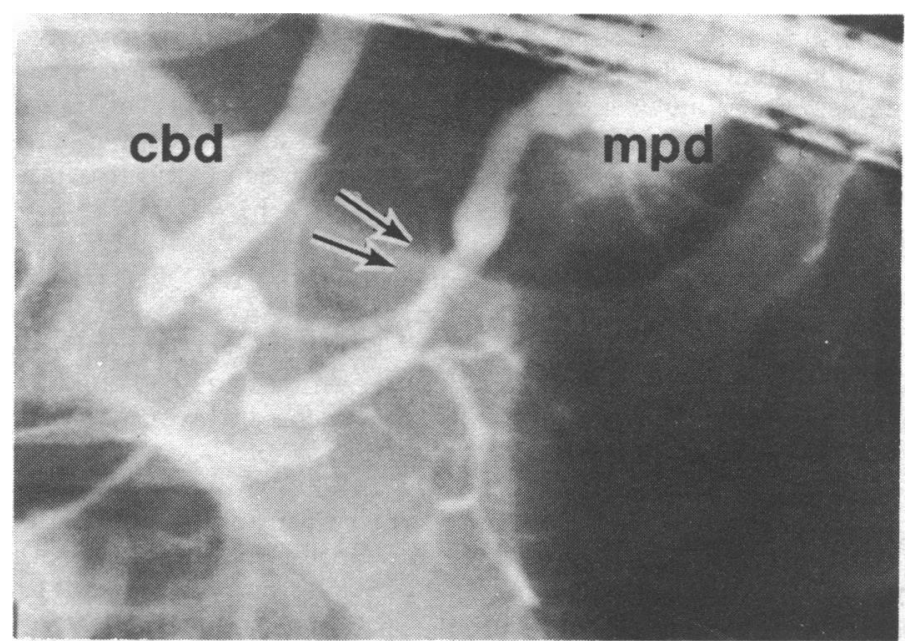

FIG. 5-Pancreatogram in man aged 43 who suffered four attacks of acute pancreatitis in two years. Main pancreatic duct (mpd) next to papilla displaced in smooth sweeping curve and narrowed (arrowed). Some branch ducts also displaced. Main pancreatic duct distal to the structure dilated. Common bile duct (cbd) filled.

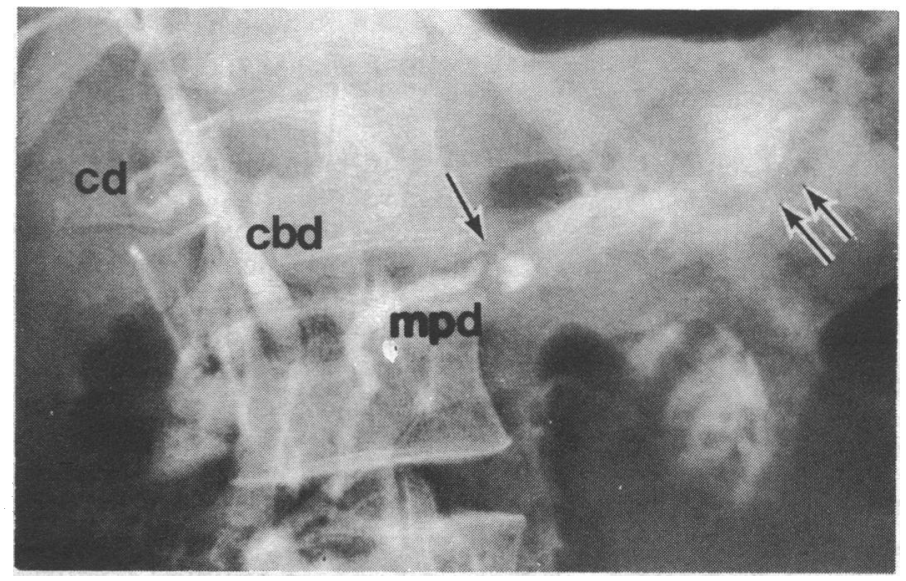

FIG. 6-Pancreatogram showing stricture of main pancreatic duct (mpd; single arrow) with small associated cyst. Duct proximal to stricture dilated. Larger cyst in tail (double arrow). Common bile duct (cbd) and cystic duct (cd) filled.

guided by the findings at pancreatography. Only one of the 13 patients whose pancreatogram showed no "surgical lesion" was operated on. This was because of recurrent severe pain. The pancreatogram had shown only minor changes in the ductal system and at laparotomy the pancreas appeared normal, but needle biopsy showed histological evidence of resolving pancreatitis. No other procedure was performed and the patient had funther attacks of pancreatitis.

Of the seven patients with complete duct obstruction or a stricture and pseudocyst five underwent the operation indicated by the pancreatogram-distal pancreatectomy or internal drainage of a pseudocyst - with good results. One patient with main duct obstruotion in the mid-body was not operated on and symptoms persisted 18 months later. Another with a similar lesion had only a sphincterotomy and continued to have attacks one year later. Two of the patients with juxtapapillary strictures underwent sphincteroplasty with good results and the remaining three with strictures continued under observation.

Of the six patients in whom a pancreatogram was not obtained three came to surgery and in each the duct was 
obstructed close to the papilla. The remaining three patients have continued under observation and all have had funther episodes of pancreatitis. Failure to obtain a pancreatogram may be due to technical problems but in experienced hands failure certainly suggests the presence of a lesion in the papillary area.

\section{Discussion}

Our study showed that about half of a group of 31 patients with relapsing acute pancreatitis had a "surgical lesion" of the pancreatic duct (obstruction, stricture, or pseudocyst) and that most of these could be shown by endoscopic pancreatography. These lesions were assumed to result from earlier attacks of pancreatitis and to have perpetuated the disease. Logically, therefore, the surgical approach should be based on the pancreatographic findings, and the subsequent course of these parients so far supponts that contention. Endoscopic retrograde cholangiopancreatography (E.R.C.P.) is not a simple procedure and needs much experience with fibreoptic endoscopes. High quality radiographs are essential and even then the interpretation of pancreatograms can be difficult. Nevertheless, this procedure seems to be the only way, short of operation, to identify a surgical lesion in the pancreatic duct.

Though the numbers in our study were small the results of measurement of pancreatic function suggested that this is not a good way of distinguishing patients with ductal disease from those without, and our experience of pancreatic scanning is equally disappointing. An alternative approach would be to perform laparotomy, duodenotomy, and operative pancreatography in every case. But operative pancreatography is not without hazand, and this can be avoided by endoscopic pancreatography. While the demonstration of a normal or virtually normal duct does not help in determining the surgical approach it clarifies the position and should suggest a need for funther search for a cause of parenchymal disease such as alcohol abuse, drug ingestion, or hyperlipidaemia. In a few such patients endoscopic retrograde cholangiopancreatography may be the only way of clearly showing the presence of gall stones.

Endoscopic pancreatography resulted in mild attacks of pancreatitis in two patients in the present series. They were the only such complications we have seen in over 300 examinations. Other experienced observers have emphasized the potential risk in patients with relapsing pancreatitis and par- ticularly in those who have pseudocysts. In these cases no attempt should be made to outline the entire cyst and the patient should be considered for surgery within the next few days. Pancreatography is contraindicated during an attack of acute pancreatitis. In patients with relapsing pancreatitis we recommend waiting for two weeks after the acute episode. Endoscopic retrograde cholangiopancreatography should always be an inpatient procedure.

We have reponted on the value of endoscopic pancreatography in a small but well-defined group of patients. Our experience with patients with painful chronic pancreatitis suggests that the procedure is equally useful in determining their surgical management. Gross abnormalities of the pancreatic duct system are more commonly seen (Kasugai et al., 1972; Classen et al., 1972). The role of endoscopic pancreatography in the diagmosis of pancreatic disease is more controversial and is currently under investigation. Evidently pancreatitis can occur in the absence of ductal changes and normal radiographs have been described in a few patients later shown to have carcinoma (Koch et al., 1973). Thus a normal endoscopic pancreatogram does not completely exclude pancreatic disease just as a normal pyelogram does not exclude renal disease. Neventheless, the present study shows that endoscopic retrograde pancreatography can provide impontant clinical information in patients with known relapsing pancreatitis.

\section{References}

Blumgart, L. H., et al. (1972). Lancet, 2, 1269.

Classen, M., Koch, H., Fruhmorgen, P., Grabner, W., and Demling, L. (1972). Acta GastroEnterologica ( $($ apan), 7, 141.

Cotton, P. B., et al. (1972). Lancet, 1, 53.

Cotton, P. B. (1972). Gut, 13, 1014

Cotton, P. B., Beales, J. S. M., and Cole, J. A. (1973). In Endoscopy of the Small Intestine with Retrograde Pancreato-Cholangiography, ed. L. Demling and $M$. Classen, p. 74. Stuttgart, Georg Thieme

Doubilet, H., Poppel, M. H., and Mulholland, J. H. (1959). Annals of New York Academy of Science, 78, 829.

Jean-pierre, R., et al. (1971). Archives Francaises des Maladies de L'Appareil Digestif, 60, 525.

Kasugai, T., Kuno, N., Kobayashi, S., and Hattori, K. (1972). Gastroenterology, 63, 217 .

Koch, H., Classen, M., and Demling, L. (1973). In Endoscopy of the Small Intestine with Retrograde Pancreato-Cholangiography, ed. L. Demling and M. Classen, p. 90. Stuttgart, Georg Thieme.

Ogoshi, K., Tobita, Y., and Hara, Y. (1970). Gastroenterological Endoscopy (Tokyo), 12, 83 .

Oi, I., Kobayashi, S., and Kondo, T. (1970). Endoscopy, 2, 103.

Takagi, K., et al. (1970). Gastroenterology, 59, 445.

Trapnell, J. E. (1966). Annals of the Royal College of Surgeons of England, 38, 265.

Vennes, J. A., and Silvis, S. E. (1972). Gastrointestinal Endoscopy, 18, 149. 